\title{
Disseminated cryptococcosis in an immunocompetent patient
}

\author{
Pradeep Mada, Brad Nowack, Beth Cady, Andrew Stevenson Joel Chandranesan
}

Infectious Diseases, Louisiana State University Health Sciences Center Shreveport, Shreveport, Louisiana, USA

\section{Correspondence to} Dr Pradeep Mada, pmada@ Isuhsc.edu

Accepted 26 June 2017

\section{SUMMARY}

Cryptococcosis is a fungal infection which is commonly associated with immune-compromised state.

Disseminated infection in immunocompetent individuals is extremely rare. We present a case of a 56-year-old African American patient who presented with unilateral knee pain and swelling and was subsequently diagnosed with cryptococcal bone mass with dissemination of infection.

\section{BACKGROUND}

Cryptococcosis is an infection caused by Cryptococcus, an encapsulated yeast organism which is prevalent in individuals who are immunocompromised or have risk factors associated with reduced immunity. It is extremely rare among people who are otherwise healthy and immunocompetent. On the basis of the population estimates from 2000, the incidence of cryptococcosis is $0.4-1.3$ cases per 100000 habitants and the case fatality ratio was 12\%. ${ }^{1}$ Cryptococcus neoformans and Cryptococcus gatti are the two species of the fungus which are responsible for almost all cases of cryptococcosis. C. neoformans is usually associated with infections in immunocompromised patients, whereas C. gatti is associated with infections in immunocompetent patients. ${ }^{2}$ Several cases of cryptococcal infections in immunocompetent patients involving different organs and organ systems have been reported. ${ }^{3-5}$ However, only a handful of cases involving disseminated cryptococcosis in immunocompetent patients have been reported in the literature. ${ }^{26}$ We report a case of a 56-year-old immunocompetent man with disseminated cryptococcosis.

\section{CASE PRESENTATION}

A 56-year-old African American man presented to the emergency department with left knee pain for 1 week after falling from his son's scooter. He reported a month-long history of night sweats, fever, chills and weight loss of approximately $20 \mathrm{lbs}$. He denied headache, cough or back pain. His medical or surgical history did not reveal anything significant. The patient had a distant history of tobacco use with two pack-years history. He reported heavy alcoholic consumption but had stopped recently, and he denied any history of drug use. He was ambulating with a cane and complained of worsening pain, swelling and 'catching sensation' in his left knee. On examination, he had pain with left knee flexion and tenderness in the posterior knee, but no swelling or visible external injury. Examination of the right knee and other joints was unremarkable. No lymphadenopathy was noted. Frontal, lateral and merchant view radiographs showed suprapatellar joint effusion and mild soft tissue swelling, but no acute fracture or dislocation was appreciated. MRI of the left knee revealed an infiltrative lesion measuring $4.3 \times 4.6 \mathrm{~cm}$ in the bone marrow of proximal tibial metaphysis extending into the epiphysis with cortical destruction and soft tissue mass (figure 1). The mass extended into the knee joint, and there was a fracture at the insertion of the posterior collateral ligament. Laboratories revealed white blood cells 5.82 thousand per cubic millilitre $\left(\mathrm{K} / \mathrm{mm}^{3}\right.$ ) (reference range: $3.6-11.2 \mathrm{~K} / \mathrm{mm}^{3}$ ) with $63.4 \%$ neutrophils, $23.6 \%$ lymphocytes, $11.3 \%$ monocytes and $1 \%$ eosinophils, erythrocyte sedimentation rate $94 \mathrm{~mm} /$ hour, C reactive protein 2.27 milligrams per decilitre $(\mathrm{mg} / \mathrm{DL})$ (reference range: $0.0-0.3 \mathrm{mg} / \mathrm{DL}$ ) and alkaline phosphatase of 123 units per litre (U/L) (reference range: 45-117U/L). Due to the concern of malignancy, staging CT scan of the chest, abdomen and pelvis was ordered. Imaging showed peripheral well-defined solid nodular lesion in the left lower lobe (figure 2) and a lytic lesion involving the cortex of the left iliacus suggesting metastatic disease. Fluoroscopic-guided fine-needle aspiration biopsy of the tibial lesion was performed by our oncologist with high suspicion of malignancy, so samples were sent to rule out malignancy and for fungal staining but samples were not sent for cultures. Pathology on the aspirates showed likely foreign material with histiocytes, giant cells and spindle cells. Fungal staining revealed the presence of fungi with histological features consistent with C. neoformans (figure 3) with mucicarmine (figure 4), Grocott's methenamine silver (GMS) stain (figure 5) and periodic acid-Schiff (PAS) stain (figure 6). Serum cryptococcal antigen titre was 1:1024. Blood fungal cultures did not grow any organism.

Lumbar puncture was performed and cerebrospinal fluid (CSF) cryptococcal antigen latex agglutination titre was 1:1024. CSF bacterial, acid fast bacillus and fungal cultures were also negative. Interventional radiology-guided biopsy of the peripheral lung lesion done and staining revealed no fungal elements on PAS and GMS stains. Liposomal amphotericin B $180 \mathrm{mg}$ intravenously once daily and oral flucytosine $1500 \mathrm{mg}$ every 6 hours were initiated for 2 weeks as an induction therapy. Workup for immune deficiency conditions, such as protein electrophoresis, immunoglobulin 


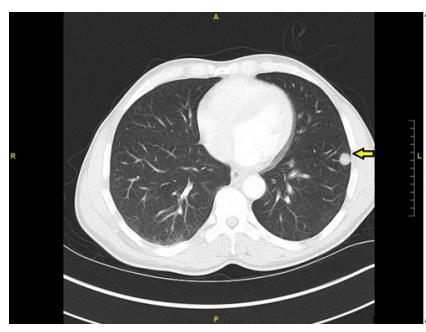

Figure $1 \mathrm{CT}$ chest showing solid nodular peripheral lesion in left lower lobe.

subclasses, cryoglobulin, HIV antibody, tumour markers and cluster of differentiation 4 (CD4) count, were within normal limits except IgE which is elevated to 410.0 international units per litre (IU/L). However, it was not sufficient on its own to make the diagnosis of hyper-IgE syndrome in this patient.

Questioning to determine exposure to Cryptococcus revealed that the patient had worked as a garbage collector in an urban area for the past 15 years. He reported exposure to bird droppings, dust and various contaminated objects during his duties. $\mathrm{He}$ also reported numerous bird nests found in his attic. The patient clinically improved during the course of induction therapy, and his left knee pain and swelling were reduced. Intravenous amphotericin B and oral flucytosine were discontinued after 2 weeks, and the patient was transitioned to oral fluconazole on discharge.

\section{INVESTIGATIONS}

Radiograph of the left knee;

MRI of the left knee;

CT of the chest;

CT of the abdomen;

Lumbar puncture;

Serum protein electrophoresis;

HIV testing;

Tumour markers;

Fungal smear of the left tibial lesion;

Fine-needle aspiration cytology of the left tibial lesion.

Relevant blood/serum test results:

White blood cells $5.82 \mathrm{~K} / \mathrm{mm}^{3}$ (reference range: $3.6-11.2 \mathrm{~K}$ / $\mathrm{mm}^{3}$ ) with basophils absolute: $0.04 \mathrm{~K} / \mathrm{mm}^{3}$, basophils relative: $0.7 \%$, eosinophils absolute: $0.06 \mathrm{~K} / \mathrm{mm}^{3}$, eosinophils relative: $1.0 \%$, lymphocytes absolute: $1.37 \mathrm{~K} / \mathrm{mm}^{3}$, lymphocytes relative: $23.6 \%$, monocytes absolute: $0.66 \mathrm{~K} / \mathrm{mm}^{3}$, monocytes relative: $11.3 \%$, neutrophils absolute: $3.69 \mathrm{~K} / \mathrm{mm}^{3}$, neutrophils relatives: $63.4 \%$, erythrocyte sedimentation rate $94 \mathrm{~mm} /$ hour, C reactive protein $2.27 \mathrm{mg} / \mathrm{DL}$ (reference range: $0.0-0.3 \mathrm{mg} / \mathrm{DL}$ ), alkaline phosphatase of $123 \mathrm{U} / \mathrm{L}$ (reference range: 45-117 U/L)

Immune deficiency workup:

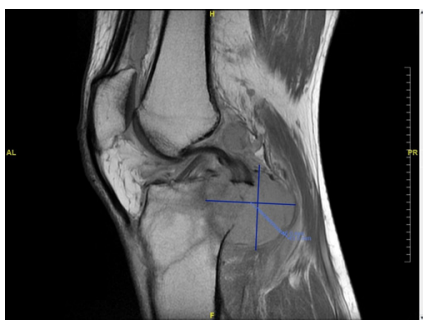

Figure 2 MRI left knee showing infiltrative lesion of proximal tibia extending into knee joint.

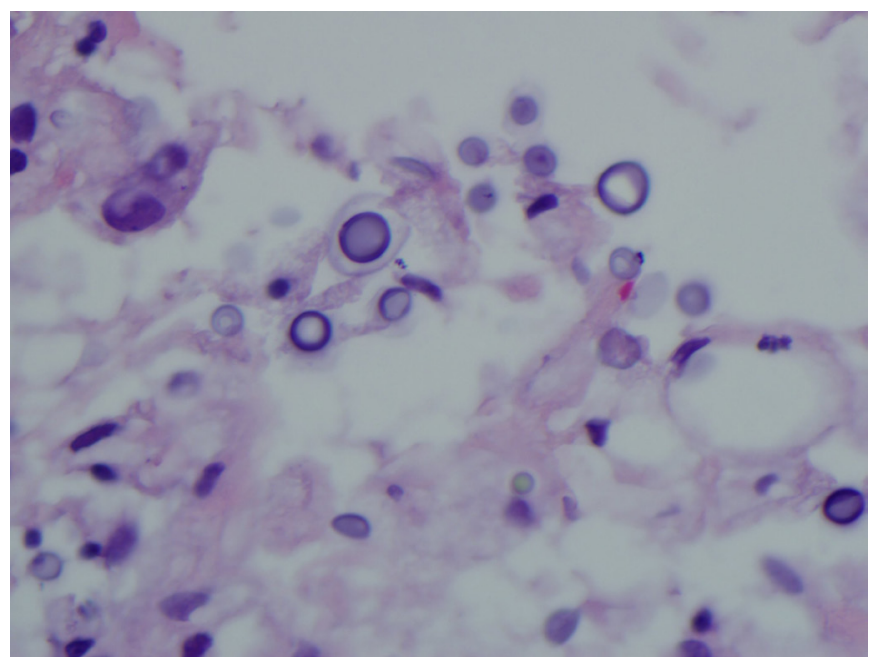

Figure 3 Gram stain showing Cryptococcus.

CD4 T cell abs: 759 cells $/ \mathrm{mm}^{3}$ (reference range: 401-1532 \#/mm ${ }^{3}$ ), CD4 \% helper T cell: $60.8 \%$, IgM total: $124 \mathrm{mg} / \mathrm{DL}$, IgA: $309 \mathrm{mg} / \mathrm{DL}$, IgE, total: $410.0 \mathrm{IU} / \mathrm{DL}, \mathrm{IgG}$, flow cytometry: $972 \mathrm{mg} / \mathrm{DL}, \operatorname{IgG} 1: 851 \mathrm{mg} / \mathrm{DL}, \operatorname{IgG} 2: 221 \mathrm{mg} / \mathrm{DL}, \operatorname{IgG} 3$ : $42 \mathrm{mg} / \mathrm{DL}, \mathrm{IgG}$ 4: $66 \mathrm{mg} / \mathrm{DL}$, free kappa light chain: $2.51 \mathrm{mg}$ DL, free lambda light chain: $1.89 \mathrm{mg} / \mathrm{DL}$, kappa/lambda fluid $C$ ratio: 1.33 (reference range: $0.26-1.65$ ratio), cancer antigen 19-9: $28.1 \mathrm{U} / \mathrm{mL}$, carcinoembryonic antigen: $1.2 \mathrm{ng} / \mathrm{mL}$, prostate-specific antigen: $0.82 \mathrm{ng} / \mathrm{mL}$, urine protein electrophoresis reveals albumin and a small amount of other urine proteins, HIV antibody negative, rapid plasma reagin: non-reactive, hepatitis $\mathrm{A}$ IgM: negative, hepatitis B core IgM: negative, hepatitis B surface antigen: negative, hepatitis $\mathrm{C}$ antibody: negative, serum histoplasma antigen: none detected, cytomegalovirus (CMV) IgG 84 AU/L, CMV IgM: negative.

CSF analysis:

Lactate dehydrogenase, CSF: 11U/L, glucose, CSF: $64 \mathrm{mg} /$ DL, protein, CSF: $51 \mathrm{mg} / \mathrm{DL}$, nucleated cells, CSF: $4 / \mathrm{mm}^{3}$ with polymorphs: $6 \%$, lymphocytes: $80 \%$, monocytes/macrophages: 14\%, red blood cells, CSF: $0 / \mathrm{mm}^{3}$.

\section{DIFFERENTIAL DIAGNOSIS}

Fungal infection;

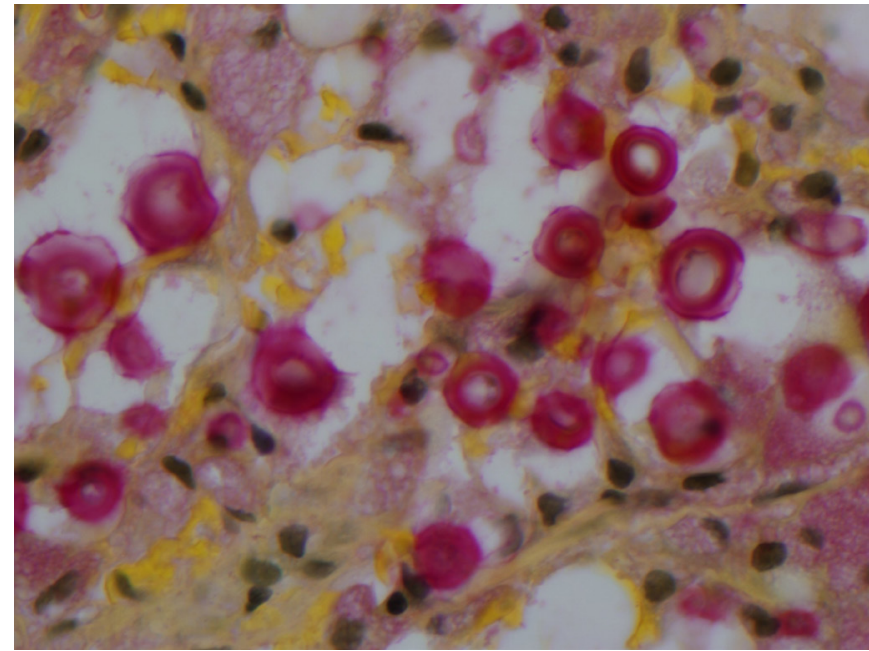

Figure 4 Cryptococcus mucicarmine stain. 


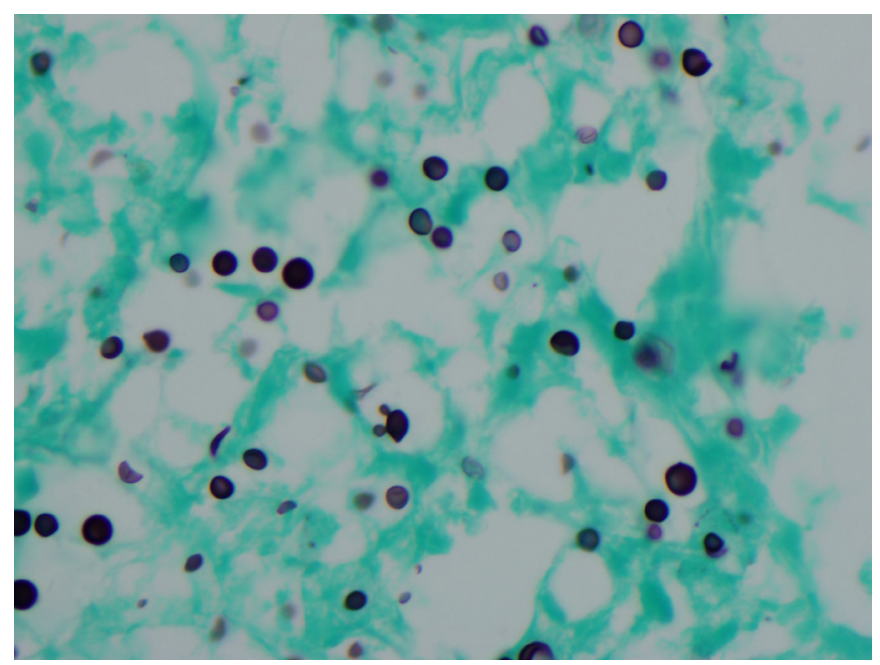

Figure 5 Cryptococcus Grocott's methenamine silver stain.

Tuberculosis;

Malignancy.

\section{TREATMENT}

Liposomal amphotericin B $180 \mathrm{mg}$ intravenous once daily for 2 weeks;

Flucytosine $1500 \mathrm{mg}$ every 6 hours orally for 2 weeks;

Fluconazole orally for 1 year after induction therapy.

\section{OUTCOME AND FOLLOW-UP}

After 2 weeks of induction treatment, repeat CSF cryptococcal antigen latex agglutination test came back negative and serum cryptococcal antigen latex agglutination titre decreased to 1:64. Therapy with oral fluconazole for 1 year was planned for maintenance after 2 weeks of induction therapy.

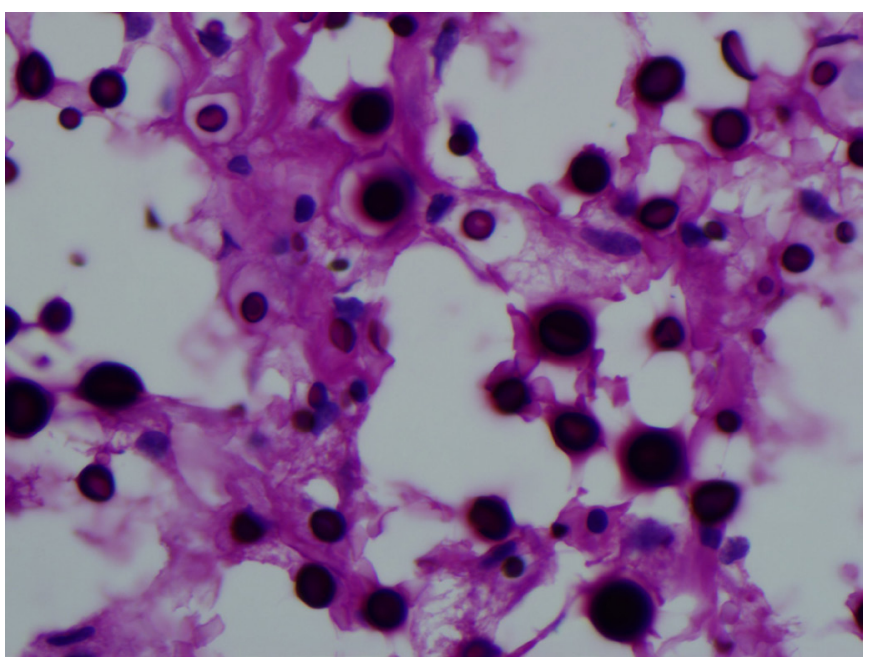

Figure 6 Cryptococcus periodic acid-Schiff stain.

\section{DISCUSSION}

Disseminated Cryptococcus infection is defined by a positive blood culture or a positive culture from at least two different sites. $^{7}$ Disseminated infection by cryptococcal species is commonly associated with HIV infection or several other immunocompromised conditions such as lymphoma or long-term immunosuppressive therapy. Very rarely, disseminated cryptococcal infection occurs in immunocompetent hosts. One case report described disseminated cryptococcal infection in a healthy individual, which involved bone marrow mimicking plasma cell dyscrasias. ${ }^{8}$ The common forms of presentation of the infection include pulmonary cryptococcosis, cryptococcal meningitis and cutaneous cryptococcosis. The organism is widely prevalent in certain regions of the world; however, the most common forms of exposure include a history of exposure to soil or bird droppings. ${ }^{9}$ In this case, the patient had a risk factor due to bird exposure at his home. The case emphasises the importance of being educated about the various presentations of disseminated cryptococcosis, including a bone or soft tissue involvement. Early diagnosis and management of this condition will significantly reduce morbidity and mortality.

\section{Learning points}

- Incidence of disseminated cryptococcal infection in immunocompetent patients is rare.

- Cryptococcal infections can manifest in a variety of clinical presentations.

- Isolated bone/soft tissue cryptococcosis at presentation is a rare finding.

- Detailed history taking plays a pivotal role in identifying the risk factors involved in cryptococcal infections.

Competing interests None declared.

Patient consent Obtained.

Provenance and peer review Not commissioned; externally peer reviewed.

(C) BMJ Publishing Group Ltd (unless otherwise stated in the text of the article). All rights reserved. No commercial use is permitted unless otherwise expressly granted.

\section{REFERENCES}

1 Mirza SA, Phelan M, Rimland D, et al. The changing epidemiology of cryptococcosis: an update from population-based active surveillance in 2 large metropolitan areas, 19922000. Clin Infect Dis 2003;36:789-94.

2 Pal P, Ray S, Patra SK, et al. Disseminated cryptococcosis in an apparently immunocompetent patient presenting with primary intraventricular haemorrhage. BMJ Case Rep 2015. [Epub ahead of print: 22 Oct 2015]

3 Gaskill T, Payne D, Brigman B. Cryptococcal abscess imitating a soft-tissue sarcoma in an immunocompetent host: a case report. J Bone Joint Surg Am 2010;92:1890-3.

4 Thompson HI. Not your "typical patient" : cryptococcal meningitis in animmunocompetent patient. J Neurosci Nursing 2005;37:144-8.

5 Núñez M, Peacock JE, Chin R. Pulmonary cryptococcosis in the immunocompetent host. therapy with oral fluconazole: a report of four cases and a review of the literature. Chest 2000;118:527-34.

6 Suchitha S, Sheeladevi CS, Sunila R, et al. Disseminated Cryptococcosis in an immunocompetent patient: a case report. Case Rep Pathol 2012;2012:1-3.

7 Yehia BR, Eberlein M, Sisson SD, et al. Disseminated cryptococcosis with meningitis, peritonitis, and cryptococcemia in a HIV-negative patient with cirrhosis: a case report. Cases / 2009;2:170

8 Abid MB, De Mel S, Limei MP. Disseminated Cryptococcal infection in an immunocompetent host mimicking plasma cell disorder: a case report and literature review. Clin Case Rep 2015;3:319-24.

9 Matsushita T, Suzuki K. Spastic paraparesis due to cryptococcal osteomyelitis. A case report. Clin Orthop Relat Res 1985;196:279-84. 
Rare disease

Copyright 2017 BMJ Publishing Group. All rights reserved. For permission to reuse any of this content visit http://group.bmj.com/group/rights-licensing/permissions.

BMJ Case Report Fellows may re-use this article for personal use and teaching without any further permission.

Become a Fellow of BMJ Case Reports today and you can:

- Submit as many cases as you like

- Enjoy fast sympathetic peer review and rapid publication of accepted articles

- Access all the published articles

- Re-use any of the published material for personal use and teaching without further permission

For information on Institutional Fellowships contact consortiasales@bmjgroup.com

Visit casereports.bmj.com for more articles like this and to become a Fellow 